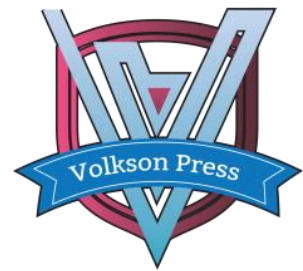

\title{
Research on Technological Innovation Strategy of Small and Medium-sized Enterprises in China Based on the Life Cycle ofEnterprise
}

\author{
Jie Sun ${ }^{1,}$, Hao Zhang ${ }^{2}$ \\ 1 Jiangsu University Of ScienceAnd Technology,Zhenjiang,jiangsu Province, China \\ 2 Jiangsu University Of Science And Technology,Zhenjiang,jiangsu Province, China \\ *972293035@qq.com
}

This is an open access article distributed under the Creative Commons Attribution License, which permits unrestricted use, distribution, and reproduction in any medium, provided the original work is properly cited.

\section{ARTICLE DETAILS}

\section{Article History:}

Received 02 october 2017

Accepted 06 october 2017

Available online 11 october 2017

\section{Keywords:}

Strategy of technological

innovation;Life Cycle of

Enterprise;Small and medium-sized

enterprises.

\section{ABSTRACT}

With the development of world economy to knowledge economy, in the natural theorem of emerging enterprises and small businesses to survive, the traditional small and medium enterprises are hard to survive in the fierce market competition, governments pay more attention to the support of small and medium-sized enterprise in policy. It is with the support of the policy that the development of small andmedium-sized enterprises with scientific and technological innovation is becoming more and more successful. It has also become the focus of the theory and policy. In different stages of enterprise life cycle ,it has different countermeasures.Therefore, this paper based on the enterprise life cycle, strategic research on technological innovation of small and medium-sized enterprises, in order to improve the competitiveness of small and mediumsized enterprises, to achieve sustainable development.

\section{Introduction}

With the gradual perfection of market economy, the acceleration of global economic integration, the market environment of the enterprise has undergone tremendous changes.Small and medium-sized enterprises will face more uncertain market competition,therefore technology competition has become the driving force and the fundamental point between enterprises. Scientific and technological innovation plays an important role in realizing the country's high-quality economic growth, improving the economic efficiency of enterprises, promoting the development of new industries and enhancing the competitiveness of enterprises. China's small and medium-sized enterprises pay more and more attention to scientific and technological innovation, in order to realize the sustainable development of SMEs.

\section{Present Situation and Problems of Technological Innovation of SMEs in China}

The overall level of scientific and technological innovation of SMEs in China is not high. At present, the main problems are as follows:

\subsection{Weakness of Entrepreneurs' Creative Consciousness}

Under the market economy condition, to promote the innovation of enterprise's science and technology,we need an entrepreneur with innovative spirit, dare to take risks and have a good vision. But for a long time, entrepreneurs' understanding of the scientific and technological innovation is not comprehensive and accurate, the lack of awareness of innovation, lack of practice and innovation, sometimes only immediate value, quick success, lack the courage to take risks and courage, in the face of technological innovation opportunities hesitant. The lack of entrepreneurial spirit has directly led to the low level of scientific and technological innovation activities of smes.

\subsection{Lag of Management}

The innovation management of small and medium-sized enterprises in China is lagging behind, which seriously affects the efficiency of scientific and technological innovation. In the initial business, the starting point of management is often low, and the characteristics of management irrationality and randomness are very prominent. In addition, due to the lack of long-term scientific and technological innovation plan and long-term scientific and technological innovation, SMEs often lack of strategic vision in the development of enterprises, short-term behavior is serious in the development of a blind pursuit of short, flat, fast project.

These management problems set a great barrier to the technological innovation of smes.

\subsection{Lack of Innovation}

First, the lack of innovative talents in SMEs has restricted the improvement of enterprise's scientific and technological level, which has seriously affected the technological innovation activities of SMEs and hindered the improvement of labor productivity. Second, it is far from enough for SMEs to rely on their own accumulated funds for scientific and technological innovation activities. They must seek funds from the outside world. However, there are few financing channels for smes. Third, the small and medium-sized enterprise technology equipment aging problems are more prominent, mainly in the backward production equipment, equipment used for long. Fourth, China's small and medium-sized enterprises are facing the exchanges and cooperation between enterprises, the lack of contact with the outside world, less information is not sufficient to cause problems such as technology and market information occlusion, backward technology, can not meet the market demand, causing a lot of waste of resources.

\subsection{Low Intellectual Property Protection Capability}

On the one hand, China has no special law of science and technology innovation, science and technology innovation failed to give the legal basis and legal protection, even if the existing legal regulations are too principle, operability is not strong, lack of legal binding force.On the other hand,although Chinese of knowledge the property has a variety of legal protection measures, the theft of intellectual property have occurred, once the theft of intellectual property, the inventor of small and medium-sized enterprises will lose benefit from innovation investment opportunities. Because of the low intellectual property protection capability, the impact on technological innovation of small and medium-sized enterprises is greater than that of large enterprises, which has shocked the enthusiasm of SMEs' innovation and restricted the scientific and technological innovation activities of smes.

\section{Characteristics and Strategic Focus of Each Stage of Enterprise Life} Cycle 
The life cycle of enterprise refers to an enterprise basically has to undergo a brewing, preparation, operation, development, to last until the demise of the recession, as one's life, from birth, growth to maturity, and ultimately to death. In this paper, the life cycle of SMEs is divided into four stages: startup, growth, maturity and recession. According to the characteristics of SMEs at different stages, the strategic focus for this stage is studied.

\subsection{Start-up Stage}

During this period, the enterprises were small in size, simple in structure and limited in resources, and because they were new entrants, they were unable to establish corporate reputation and corporate image, so it was difficult to obtain assistance from outside the enterprise. At this point, the biggest task of the enterprise is to survive, and how to get more room for survival is the biggest task facing the enterprise. The key point of technological innovation strategy of small and medium enterprises is to get rid of the predicament of survival. It includes: satisfying the market demand and improving the level of science and technology; establishing the property right incentive mechanism with scientific and technological personnel as human capital; developing its own system.

\subsection{Growth Stage}

At this time, the customer gradually familiar with the enterprise, enterprise products or services have basically been recognized by the market, has survived the crisis of survival. Enterprises should strive to expand market share, enhance corporate awareness, establish a good corporate image, and strive for more loyal customers, and constantly accumulate management experience and technical strength. At this point, the strategic focus is to establish long-term enterprise development goals, and enter a large-scale development period. Including: to prevent the founder of "trap", the enterprise vitality and organizational structure to be institutionalized, to form a course of action, system of clear regulations and improve the budget system; to continue to vigorously implement the innovation spirit; improve the incentive mechanism, strengthen the construction of talent team.

\subsection{Mature Stage}

At this stage, the enterprise has a high market share, good corporate image and reputation and stable

customer base, and the enterprise internal personnel quality, management level, technical strength through continuous accumulation stages before has reached a higher level. The competition is getting worse, the price of products is lower, the cost of selling is increasing, and the profits of enterprises are decreasing. At this point, the strategic emphasis is on reshaping the corporate culture of innovation. Including: the management of the enterprise, to update the concept of this change relates to enterprise management direction, development strategy, organization, operation mode, the allocation of resources and a series of means and methods, management is the foundation of the enterprise culture construction.

\subsection{Recession}

The main characteristics of the recession are: first, sales, profits declined sharply, showing negative growth; second, products, equipment and process aging; third, the enterprise thought is rigid, a serious lack of innovative awareness. At this stage, the strategic focus is to quickly get out of the predicament, step out of the crisis and prolong the life of the enterprise. Specific include: the signal for the recession crisis and recession crisis should pay enough attention to, have made predictive decisions; looking for new products or services, process innovation.

4. Characteristics of Each Stage of Enterprise Life Cycle and the Strategic Choice of Technological Innovation

According to the different stages of the enterprise life cycle, the appropriate strategic models of technological innovation are selected, the specific content is shown below:

4.1 Start-up Stage--Cooperative Innovation Strategy and Imitative Innovation Strategy

\subsubsection{Main Points of Implementation of Imitative Innovation Strategy}

First, targeted research and development. A strong targeted imitation of a link or process in a technological innovation chain that mimics a goal. Second, control and complete matching resources. Only in this way can the enterprise develop its capabilities and make it possible to develop further. Third, we should correctly handle the relationship between legal protection barriers and imitative innovation. The correct approach is not to imitate, but on the basis of the imitation further, not only to lead the accumulation of technology to digestion and absorption, and on this basis to carry out new exploration, and strive to improve the performance, quality and reduce the cost of product innovation.

\subsubsection{Main Points of Implementation of Cooperative Innovation Strategy}

Demonstrated good team spirit. Enterprises in the early stage of cooperative innovation, mostly for the survival of enterprises should pay more attention to cooperation with research institutes, universities and colleges. The scientific research institutes, universities and entrepreneurs in pursuit of the goal is not consistent, meet all kinds of contradictions can hardly be avoided should show the enterprise, good spirit of cooperation, the contradictions do not immediately blame, but to solve the problem is the core reason to resolve conflicts.

\subsection{Growth Stage--Imitative Innovation Strategy and Cooperative Innovation Strategy}

\subsubsection{Main Points of Implementation of Imitative Innovation Strategy}

First, formulate the long-term development strategy of enterprises, and guide the selection of scientific and technological innovation strategy accordingly. Second, to prevent "founder trap", to institutionalize enterprise vitality and organizational structure, to form a clear policy of action, systematic rules and regulations and a sound budget system. Third, mass production of innovative products to achieve large-scale production, and continue to improve manufacturing capacity. Fourth, equipped with a market innovation capability of the personnel team, to achieve low-cost sales effectiveness.

\subsubsection{Main Points of Implementation of Cooperative Innovation Strategy}

Focus on management coordination, prevent organizational risk. In the period of growth of SMEs, although the ability of technological innovation of enterprises has been improved, the management ability of enterprises is still not strong, and the problem of management coordination is easy to be encountered in the process of implementing cooperative innovation strategy. Enterprises should establish a management coordination mechanism, correctly handle the relationship between the members of cooperation, and prevent problems arising from cooperation among members, which will bring risks to enterprises.

\subsection{Mature Stage--Independent Innovation Strategy and Cooperative Innovation Strategy}

\subsubsection{Main Points of Implementation of Independent Innovation Strategy}

First, correctly assess the ability of enterprises to take risks, we can not blindly implement the strategy of independent innovation, while ignoring its high risk. Second, cultivate enterprise innovation culture. The management idea of enterprise is the key to cultivate enterprise innovation culture. Third pay attention to the protection of intellectual property rights, and further determine the monopoly status of science and technology in law. Fourth, pay attention to self-improvement of innovative products to meet different levels of market demand and the majority of users to improve product quality and performance, increase product variety requirements.

\subsubsection{Main Points of Implementation of Cooperative Innovation Strategy}

Pay attention to the protection of core technology. In the mature period, core technology is the key to success. The implementation of cooperative innovation strategy, if the enterprise is capital equipment support through cooperation, so enterprises should establish the core technology protection mechanism, the source from the development, the core technology of the development process and other aspects of the protection of core technology. If the enterprise is cooperative development of core technology, then ownership is the key issue, we should establish a mechanism of cooperation and innovation of revenue and risk, to achieve shared interests, risk sharing, complementary advantages.

\subsection{Recession--Imitative Innovation Strategy}

\subsubsection{Main Points of Implementation of Imitative Innovation Strategy}

Pay attention to the perfection of original science and technology. SMEs in the recession, a large number of idle resources, enterprises have been unable to achieve the allocation of new resources, and if enterprises can not 
realize the full use of idle resources, the enterprise can not afford to extend the life cycle. On the basis of the original science and technology, they should follow the new market leading enterprises to realize the performance improvement and upgrading of the enterprise's technology.

\section{Conclusions}

Based on the enterprise life cycle theory and technological innovation theory, through the analysis of the various stages of the life cycle of small and medium sized enterprises of science and technology innovation strategy, we discusses the small and medium-sized enterprises according to the stages of the life cycle of the strategic mode of technological innovation,which is a reasonable and effective choice. This choice is a matching analysis of applicability analysis. Therefore, we must have the dynamic adjustment of the idea in the enterprise selection and implementation of technological innovation strategy and review of the implementation of the strategy and business development timely, to adapt to the development of the enterprise technology innovation strategy or details of constant adjustment and improvement.

\section{References}

[1] Freeman,Chris and Soete.The Economic of Industrial Innovation(Third Edition)[J]. London. 2013,21(1):263-264.

[2] Yuanmiao Cui.Research on the Choice of Scientific and Technological Innovation Mode Based on the View of Enterprise Boundary[D].Shanghai:Fudan University,2015.

[3] Chunhui Tang,Yaojia Tang.Analysis of Scientific and Technological Capability and Innovation Mode[J].Journal of Liaoning University(Philosophy and Social Sciences Edition),2016,43(1):34-35

[4] Xuemin You.Science and Technology Innovation Strategy of Private Hightech Enterprises in China[J].Reform and Strategy,2015,9(6):23-25.

[5] Guisheng Wu,Wei Xie.Strategic Thinking on the Development of Science and Technology Management Discipline in China[J].Management of Research and Development,2015,21(6):49-55 